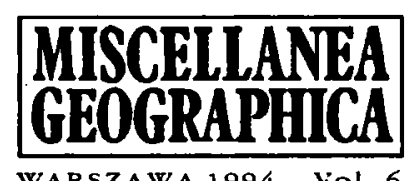

WARSZAWA 1994 Vol. 6

Jadwiga Tomalkiewicz

\title{
SPACE IN THE IMAGES OF CHILDREN AND YOUTH
}

This survey of the images of children up to 8 years and youth up to 18 years was conducted in schools in towns and villages in the years 1992 and 1993. 391 pupils were interviewed: 211 from towns of various size - Warsaw, Olsztyn, Białystok, Konin, Siedlce, Mińsk Mazowiecki, Żelechów, as well as 180 pupils from the villages of the Białystok voivodship, Marki n.Warsaw, Kołaki Kościelne in the Lomża voivodship and Gwizdały in the Siedlce voivodship.

Schools from urban and rural milieus were chosen for the survey since it was assumed that there would be major differences in perceiving space due to the influence of the nearest neighbourhood, which differs in towns from that in villages.

It was also assumed that the conception of space in so differentiated groups will be clear-cut and it will be described in such a way as to permit the grasping of the relationship between the description and the space surrounding children and youth in their everyday life.

The question about the conception of space was put as an open task; the respondents were told to draw and describe what they were asked. Younger children (aged 8-10 years) were asked to draw, while pupils of higher grades were to describe space. An open form of the control task enabled the pupils to make use of their knowledge and individual experience, as it was expected that there might be a clear-cut difference in handling the information coming from the various sources of knowledge. Besides, it was assumed that the individual "world" of the pupil's sensations, his sensitivity and extra-school interests would be mirrored in the way of approaching the problem, as well as in the selection and scope of the information conveyed about the space.

It was expected that the younger and older children would draw and describe the space as they perceive and understand it, using the means of expression, i.e. form and language adequate to their age.

The survey was also intended to check how the pupils would describe spatial features, i.e. three-dimensional character, boundaries and the relation between the space and themselves (whether they perceive that they are 
a component of space) and whether they perceive that there occur phenomena and processes in space in a different time (relative and absolute).

Taking into account the fact that geography is a chorological science, the survey among pupils was made in each school by a geography teacher during the class of this subject. It was expected and even assumed that the investigations, through the answers of the pupils, would show the influence of geography teaching on the shaping of the image of space in their minds.

It was even anticipated that the investigations would reveal how this image is enriched with age in increasingly new contents and perhaps would enable the grasping of the successive development stages of this conception; the age group 8-18 years was questioned, so that this expectation was not groundless.

The age and environmental structure of the group of pupils (391) under investigation was as follows:

Table 1

\begin{tabular}{|l|c|c|c|c|}
\hline \multirow{2}{*}{ Environment } & \multicolumn{4}{|c|}{ Age group } \\
\cline { 2 - 5 } & $8-10$ years & $10-12$ & $12-14$ & $14-18$ \\
\hline Towns & 36 & 43 & 50 & 82 \\
Villages & 38 & 72 & 70 & 0 \\
\hline Total & 74 & 115 & 120 & 82 \\
\hline
\end{tabular}

The results of investigations of the images of space in all age and environmental groups appeared to be astonishing, which is confirmed by the statements of the pupils. The sense of these statements will be illustrated by the following examples:

- "The interplanetary space is the area among planets" (schoolboy, aged 18); - "Space is a vacuum in the outer space" (schoolboy, aged 17); "Space is in places where there is nothing" (schoolgirl, aged 15, rural area); "Space is what you can see between the rails in a fence" (schoolboy, aged 12; rural area); "Space is an empty place between the mountains" (schoolgirl, aged 12; urban area); "If there is an interval between the walls, it is a space" (schoolgirl, aged 11; urban area).

The age structure of the children interviewed from 8 to 18 years of age differentiates cognitive abilities of the pupils. This is the time of passage from thinking by use of concrete images (8-12 years) to logical thinking (12 years and more). Hence, no uniform criteria can be used for the population under investigation.

Children aged 8 years were asked to draw their images of time and space. Time occurred in all works as watches of various shape with hours marked on them, while space was presented as various landscapes (including forest, sea, beach, and buildings over which clouds and sun were marked), as well as representations of the outer space with planets and space aircraft. 
All the works at this age level (8-10 years) show, regardless of the environment, that the foundations of the images of space are satisfactory and are a sign of the further correct evolution of this concept.

At the age level of 10-12 years space is understood as the landscape containing few buildings, as well as fields and meadows. This kind of images is characterized by the following statements: "Fields, meadows may be called space"; "Space is a large amount of terrain or room".

This is the image of space among children living in towns, as well as of those living in rural areas.

13-year old children emphasize in their description of space the following factors: feeling of emptiness and identification of space with the outer space - something enormous that cannot be seen as a whole.

14-year old children begin to try to measure space, for example "... space is a distance which has no end", "... the outer space is an interval in the outer space", "... space is an area of land, ... however, it is a limited space". In this age group, the above-mentioned statements constitute $58 \%$, while the remaining pupils (42\%) identify space with a vacuum, lack of things and emptiness.

In the age group of 15 years (pupils of the last grade of primary school), one pupil of urban environment names three-dimensionality for the first time ("...because space is three-dimensional)...".

In summing up the results of surveys conducted in the age group 8-15 years on the images of space, it should be concluded:

- the image and understanding of the concept of space is rooted in intuitive emotions expressed by the language of everyday speech;

- pupils are not aware that they, too, are a constituent element of space, or maybe nobody convinced them in a sufficient way; they treat space as "...something beyond them".

- no statement concerning space included information about the processes and phenomena occurring in space;

- space is perceived by the pupils interviewed as something static.

- almost all statements show that the image of space does not include what we call space boundaries. It means that the pupils interviewed do not realize that the space they perceive is part of general space. This conclusion is illustrated by the statement: "...for me, space is an enormous state",

- urban and rural pupils talk about space in a similar way, as regards the language of statements and the "world" of associations,

- pupils do not associate the concept of space with the closest surroundings, district, village, commune or voivodship.

The results obtained may be connected with the way of geography teaching and learning and make us formulate the following statement:

- pupils, who do not understand the concept of space, will not be able to explain correctly the notion of a geographic space, that is the concept being one of the major purposes in geography teaching.

This conclusion is confirmed by the surveys conducted to analyze the 
image and understanding of the concept of space in secondary school in the age group 16-18 years. Out of 82 pupils interviewed only 9 statements managed fully to meet these requirements by mentioning the most important features of space. Taking into account the fact that the secondary schools are attended by select youth, the number of correct solutions was found to be surprisingly low, and the level of statements exhibits great differences. One group consists of statements resembling those of the children aged 14-15 (primary school), for example:

"I associate space with the desert, steppes, sea, precipice in the mountains..."; "space is the world, outer space, universe, place as well as everything that surrounds us".

Another group of statements ( 46 pupils) comprises incomplete answers, e.g.:

- "space from the astronomical viewpoint is the universe, infinity, planetary systems, stars and vacuum... The Earth will all the continents, seas and the interior... "Space in agricultural and economic approach..."

The third group of statements comprises those answers which were formulated in the following way: "space is a three-dimensional area in which all the material beings exist..."; "space is an unlimited area..."; "space has tangible determinants which allow us to define it".

The investigations also revealed that the concept of space is of philosophical nature to many pupils; it is closely connected with the world outlook and God.

To sum up, one of the purposes of geography teaching included in the slogans of the programme "Space in which I live, space that surrounds me, space which is transformed by me" is very difficult to accomplish and needs - in the course of teaching - integrated actions of teachers of all subjects, not only those of natural sciences. 



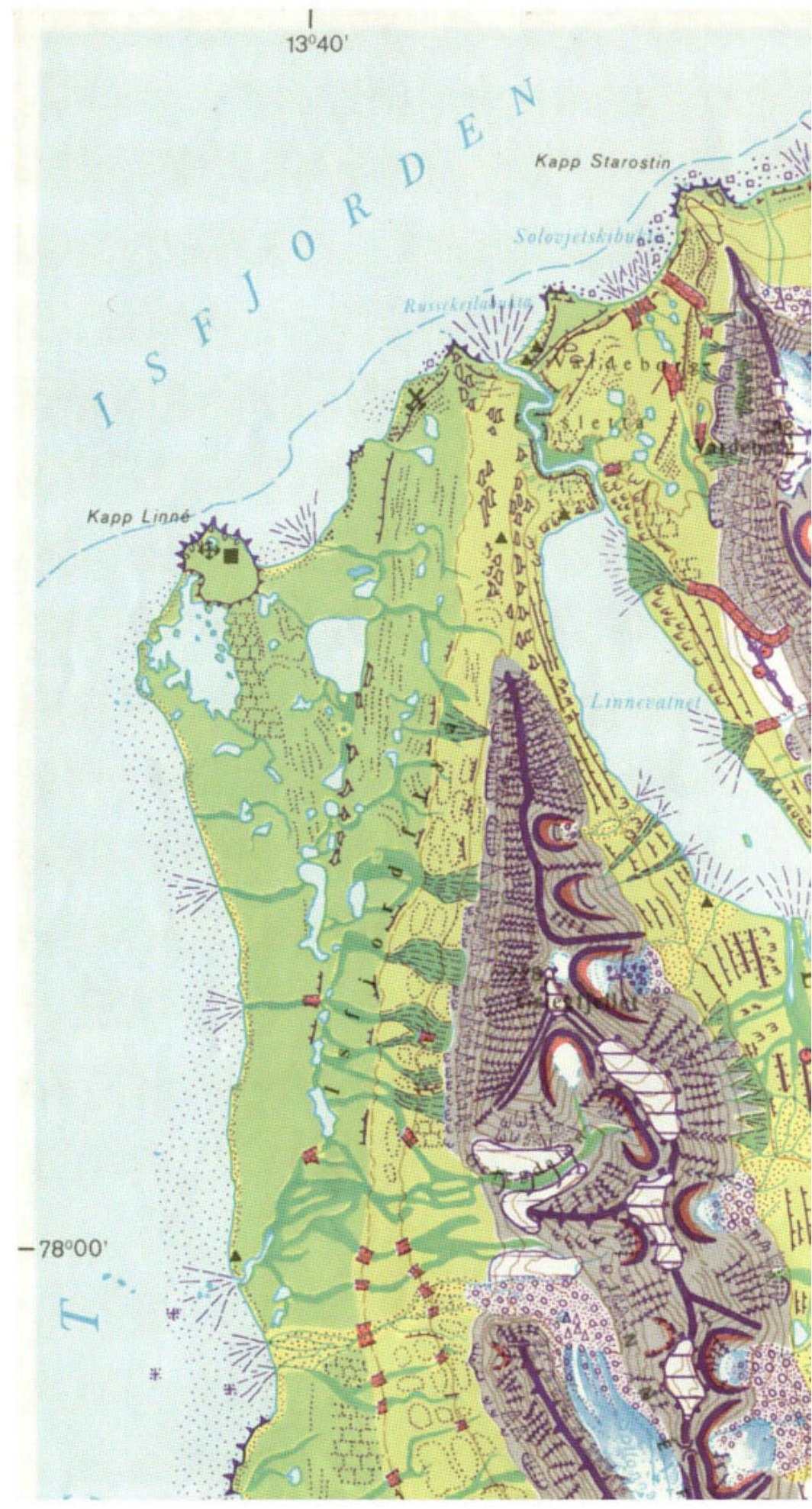


$14^{\circ} 00^{\prime}$
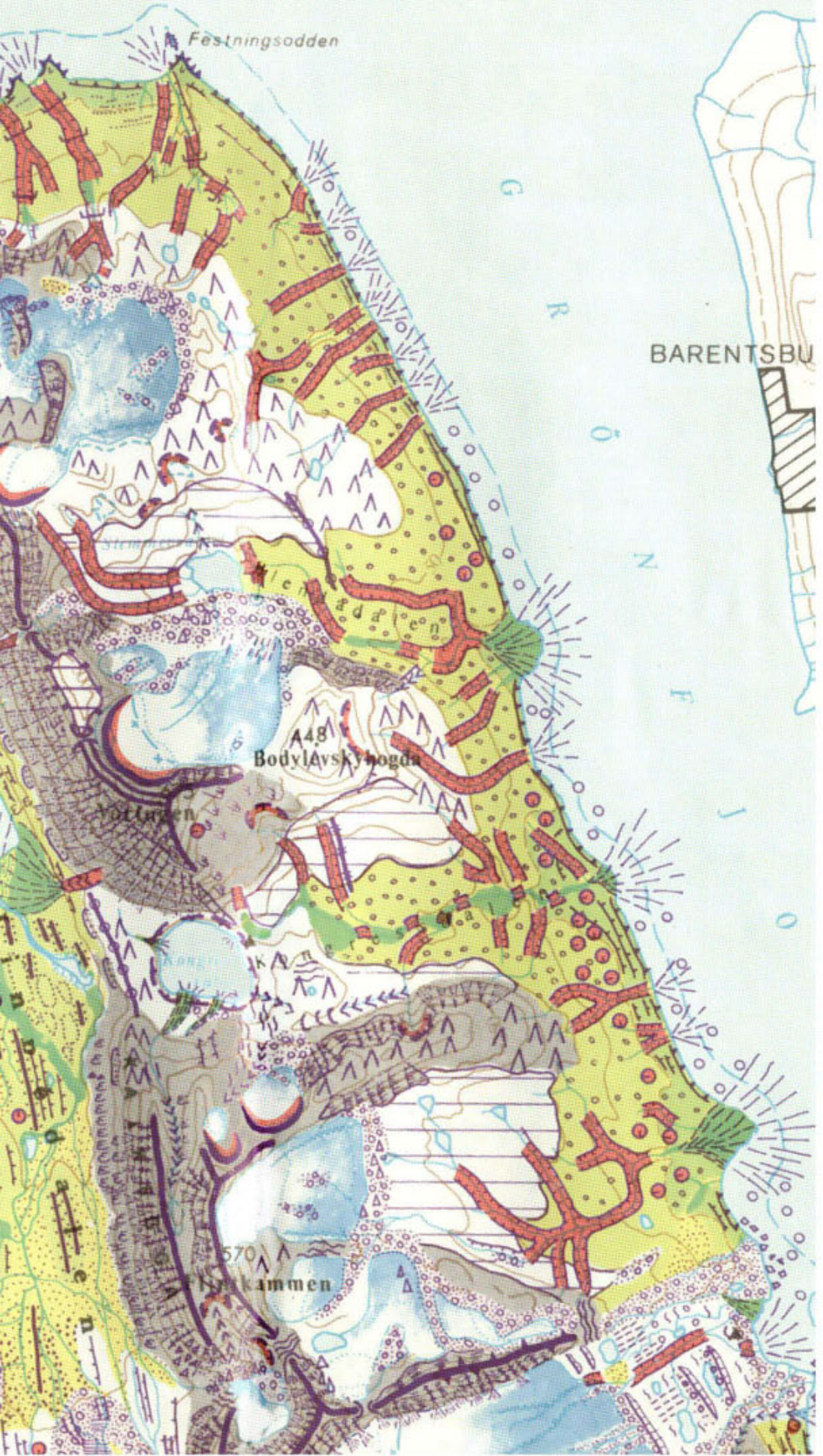


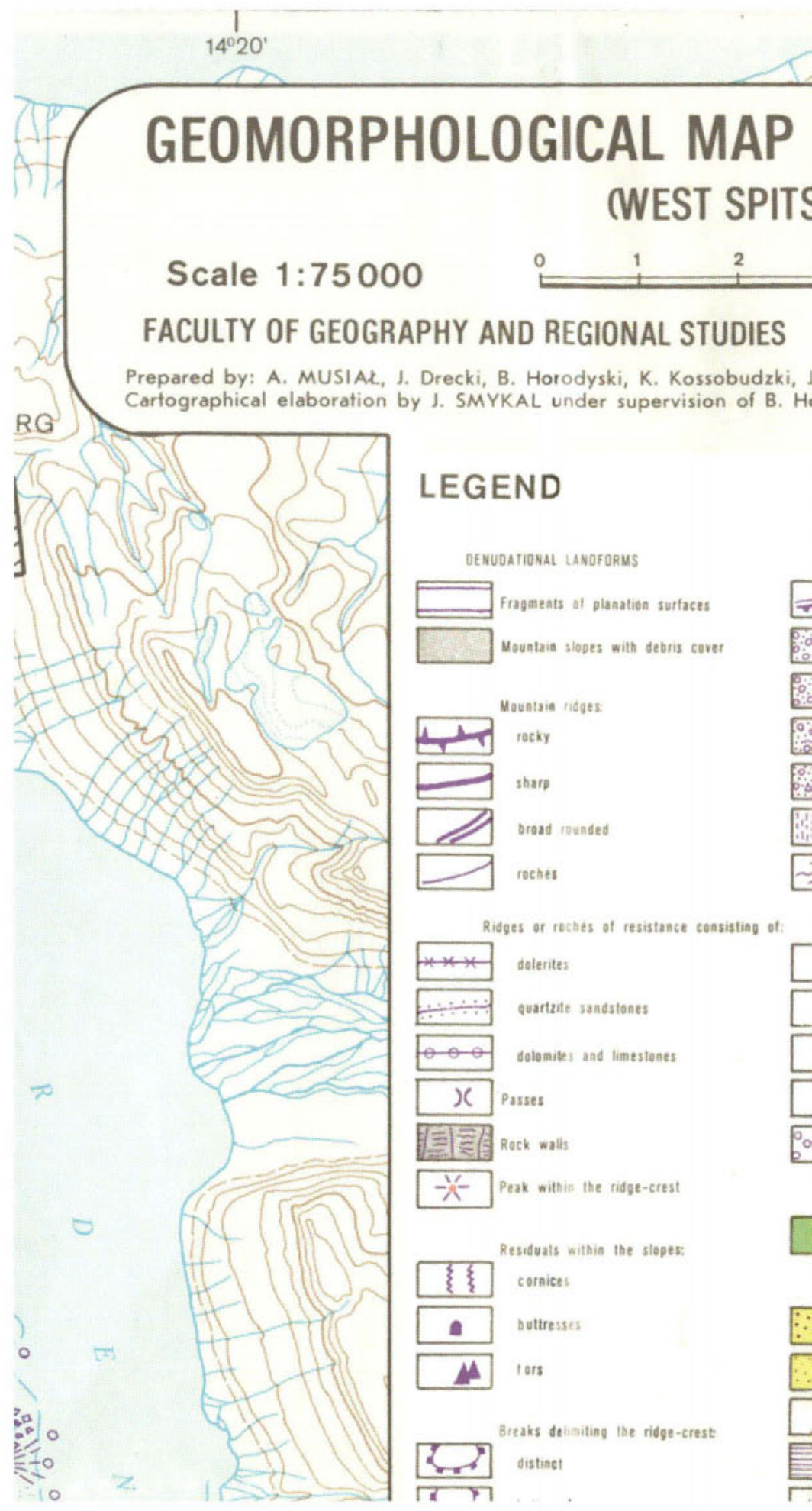




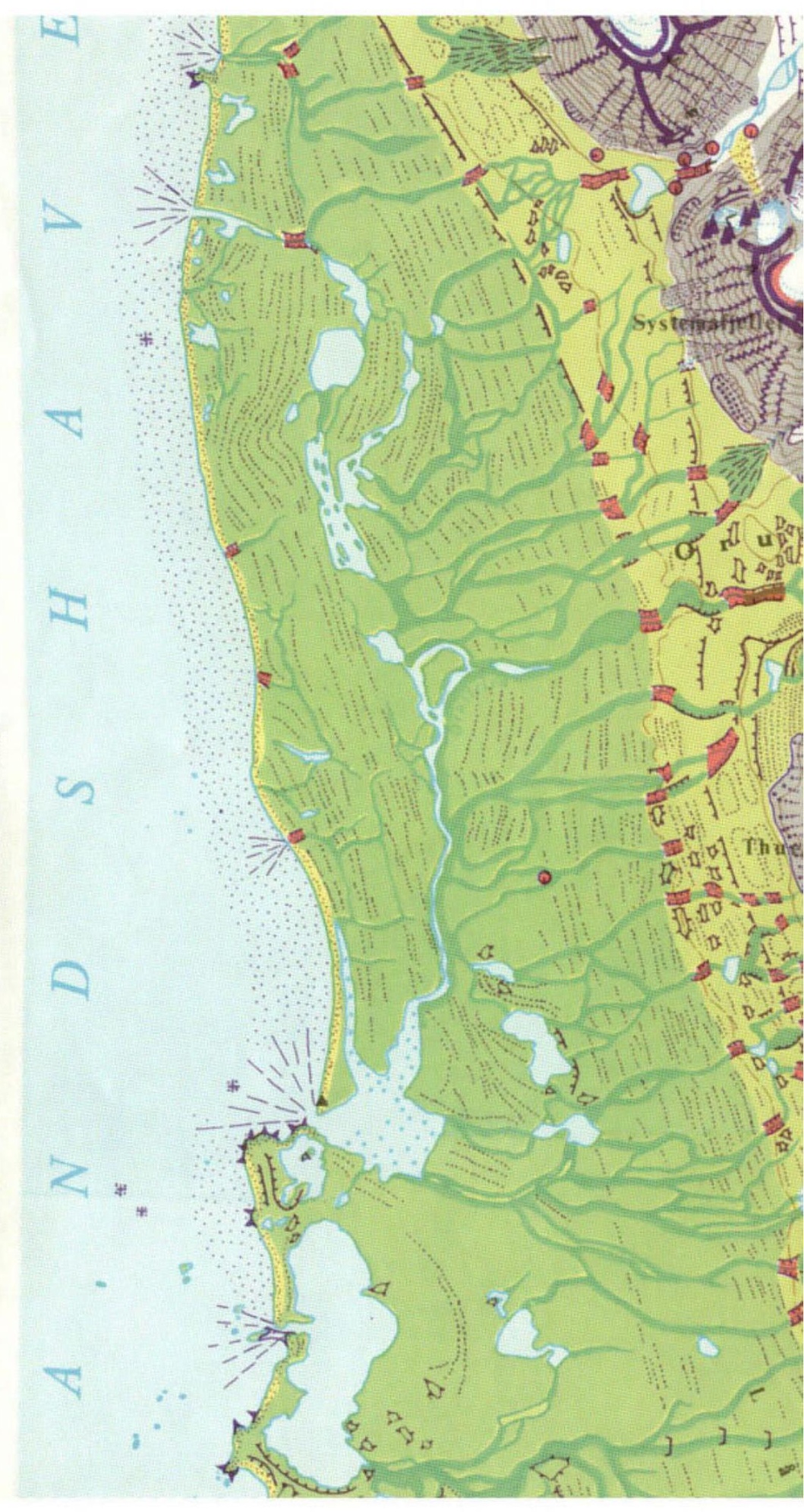




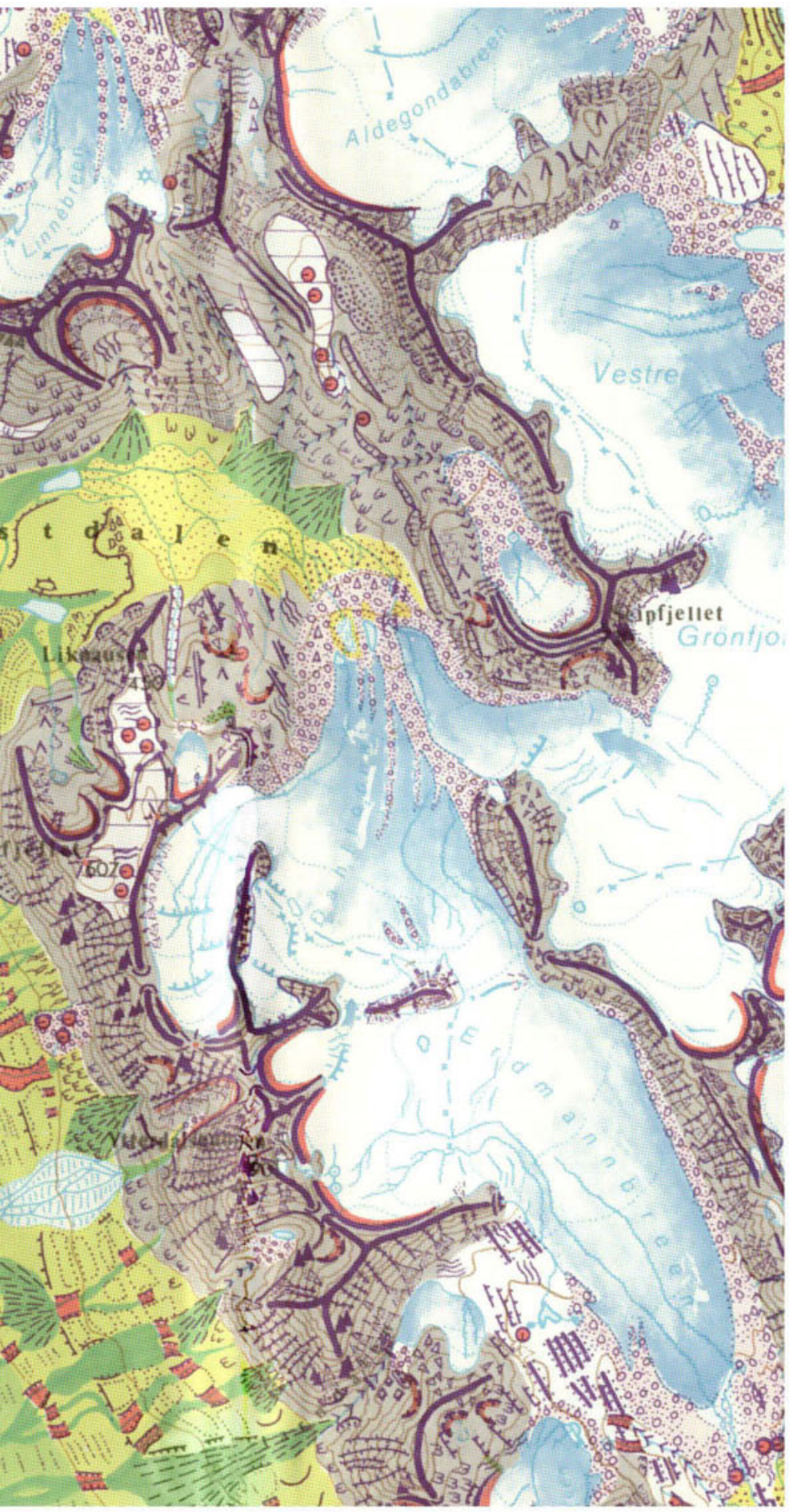




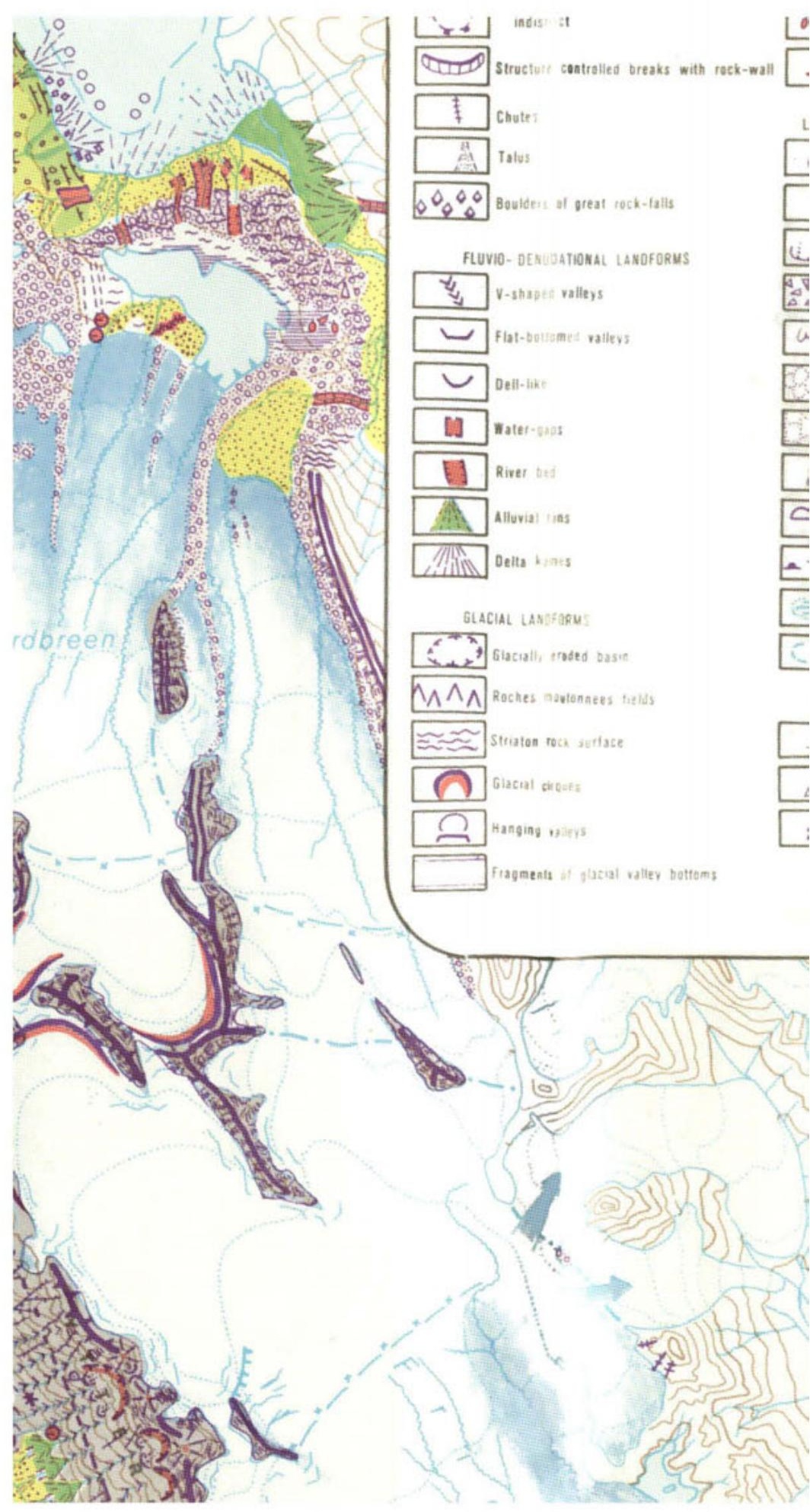


O $D$ kame nas and tager

AtP Eskers hills and ridges

L't Neve liae

xhe Moulin

ANDFORMS OUE TO NIVATION ANO FROST ACTION 0

1 Nival ciraues

$\$$ Glacial comasion

(a) Snevt of glacier

c.07 Dead ice blocks

i.iv Nival maraine ridges

D... Ine divides

$\triangle 405$ Felsenmet

Wv Solifiustion tongue

PYT Ice elifts

mornglacial steps

Z_andaciers crevasse

Supraplacial streams

1936 Land extent of glaciers

4 icebers track

Initiat pingos

ADUTIONAL SINGS

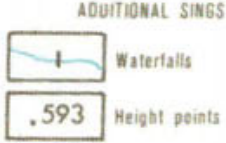

E Inhabited buts

A Irapper buts

Caves

3 Limestoses and dolomites ters

$x$ old mines

8 Gypsifereus tors

if Radio stations

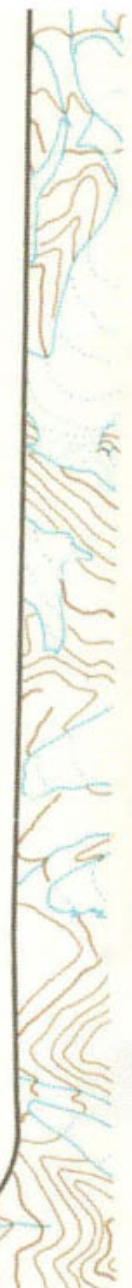

(The map was prepared basing on a Norwegian Topografisk kart over Svalaard 1:100000)

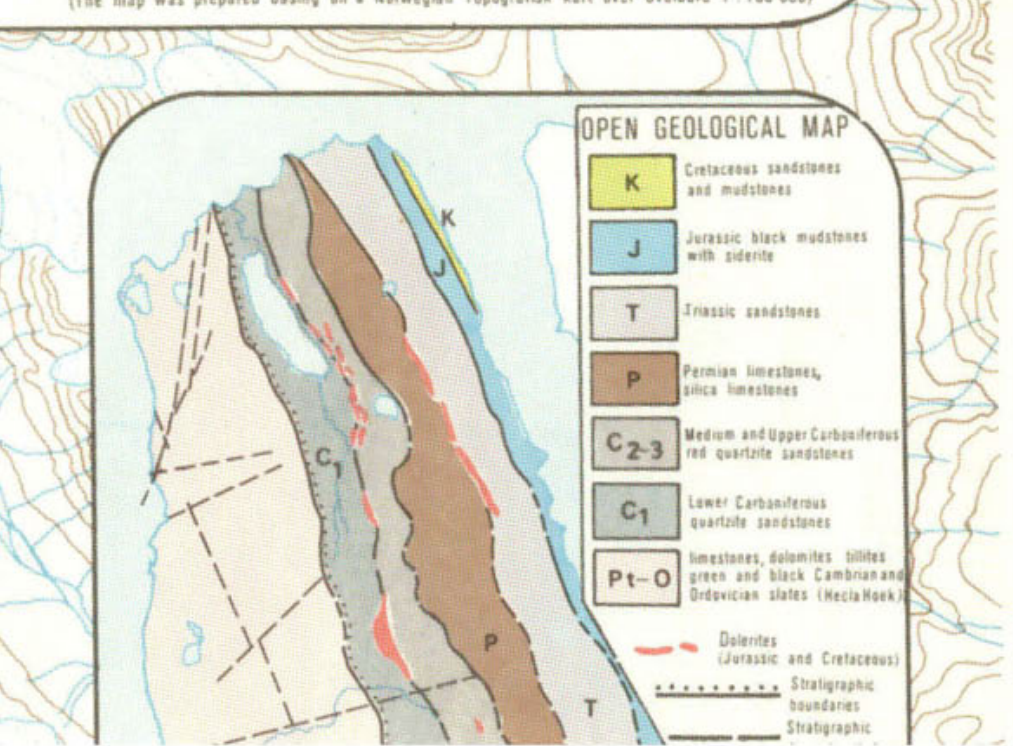




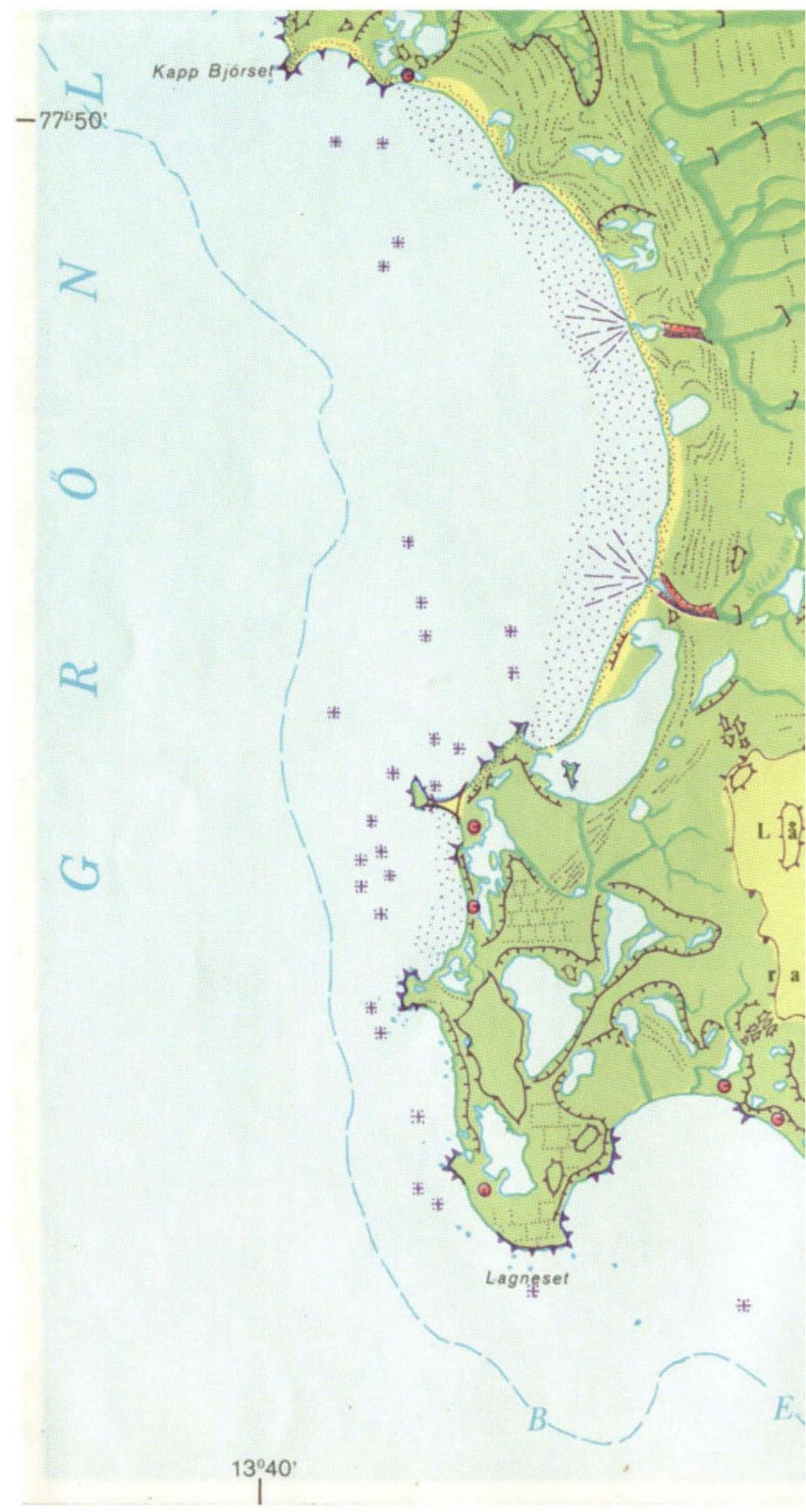




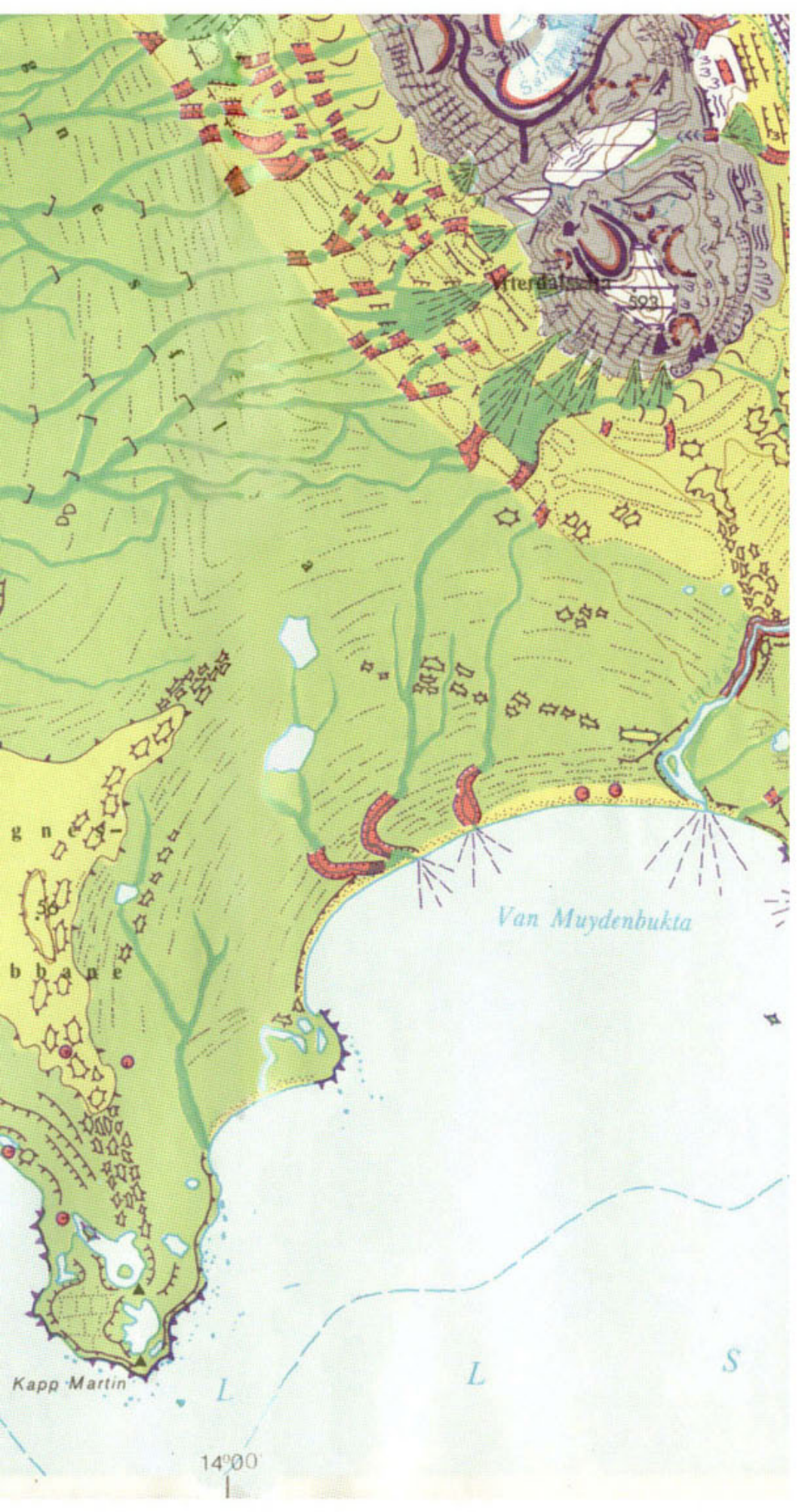




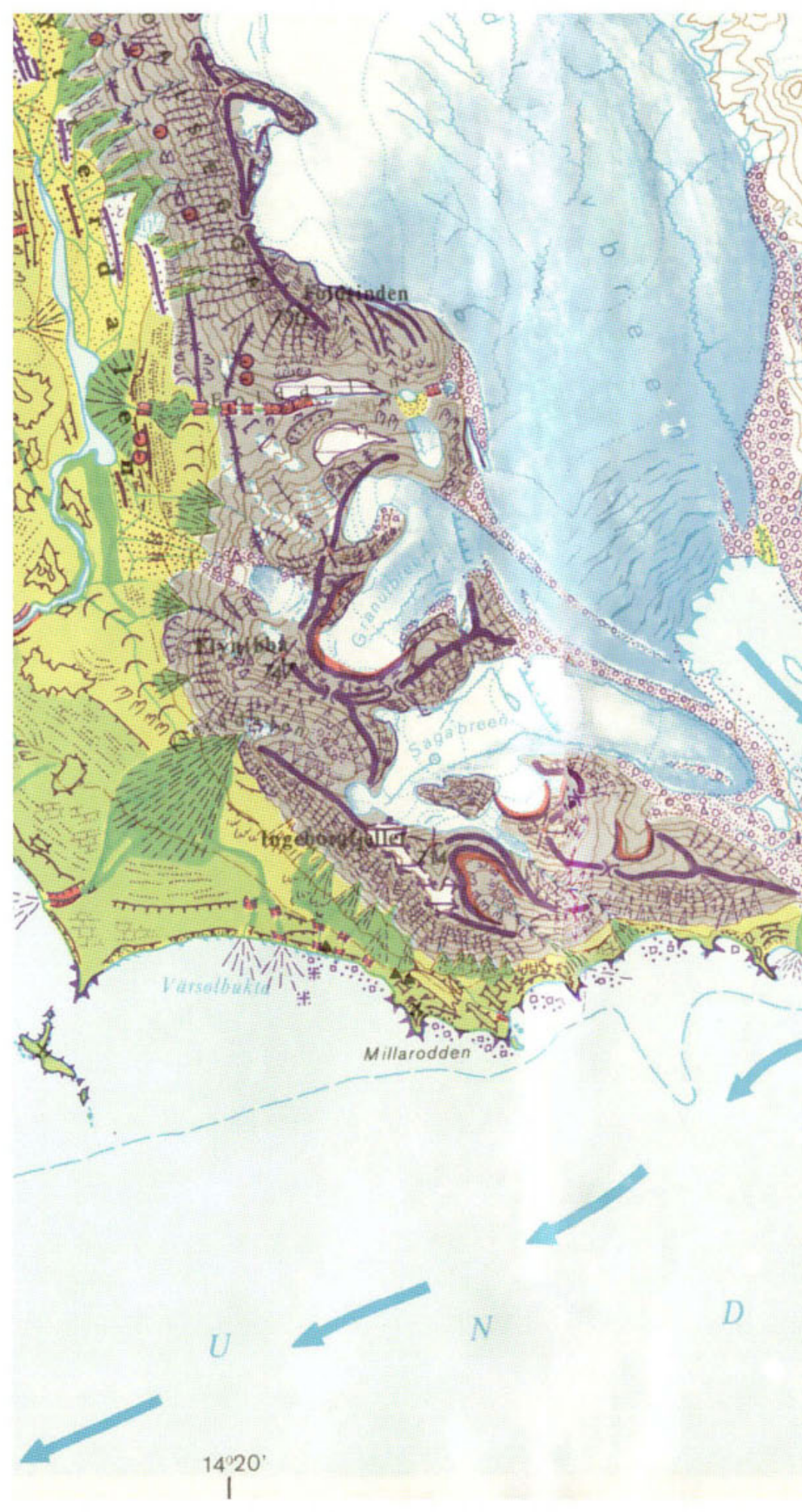




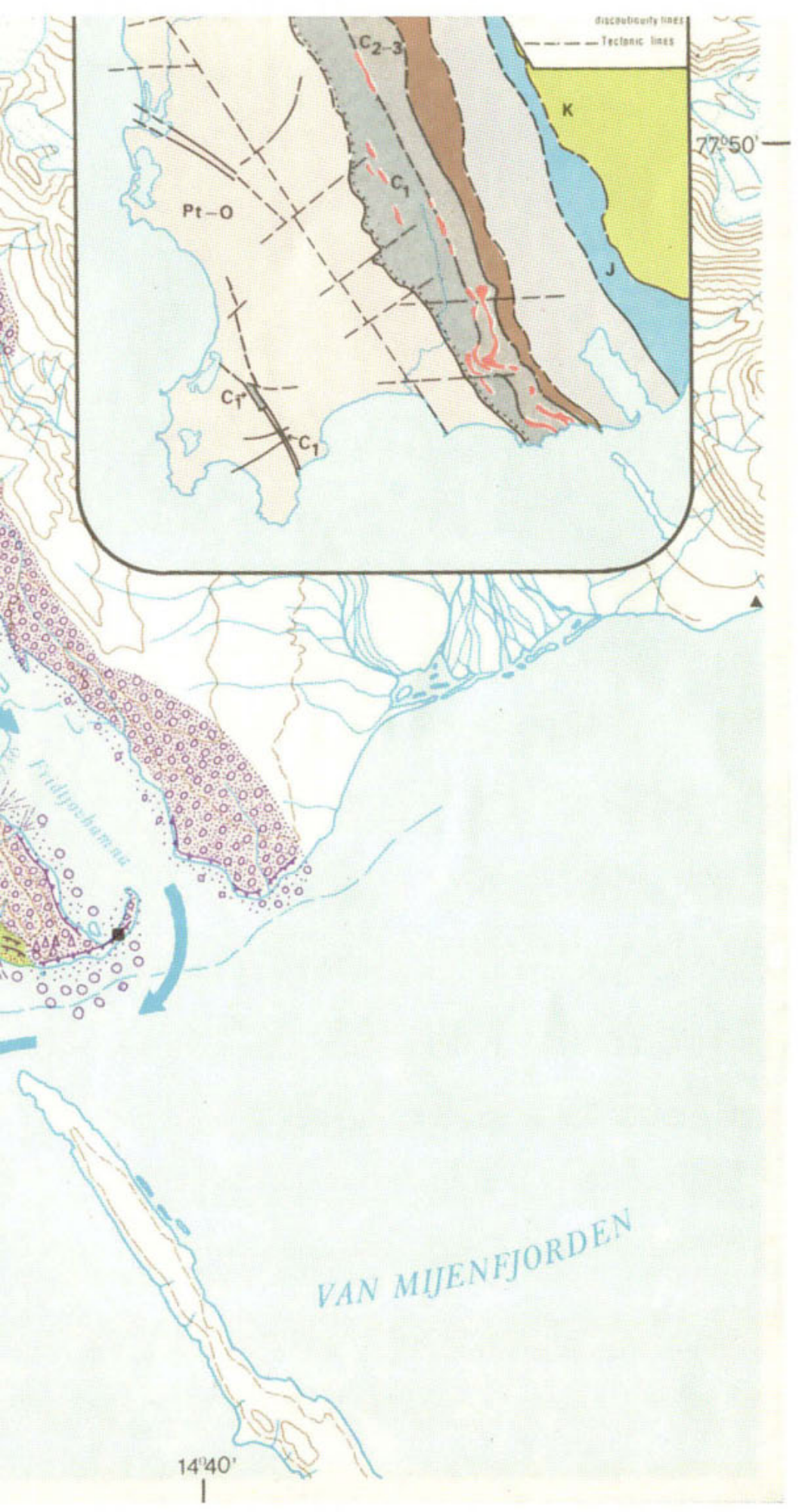

